\title{
Optical properties in the UV and visible spectral region of organic acids relevant to tropospheric aerosols
}

\author{
C. E. Lund Myhre and C. J. Nielsen \\ Department of Chemistry, University of Oslo, P.O. Box 1033 Blindern, N-0372 Oslo, Norway
}

Received: 28 March 2004 - Published in Atmos. Chem. Phys. Discuss.: 3 June 2004

Revised: 31 August 2004 - Accepted: 31 August 2004 - Published: 3 September 2004

\begin{abstract}
Refractive and absorption indices in the UV and visible region of selected aqueous organic acids relevant to tropospheric aerosols are reported. The acids investigated are the aliphatic dicarboxylic acids oxalic, malonic, tartronic, succinic and glutaric acid. In addition we report data for pyruvic, pinonic, benzoic and phthalic acid. To cover a wide range of conditions we have investigated the aqueous organic acids at different concentrations spanning from highly diluted samples to concentrations close to saturation. The density of the investigated samples is reported and a parameterisation of the absorption and refractive index that allows the calculation of the optical constants of mixed aqueous organic acids at different concentrations is presented. The single scattering albedo is calculated for two size distributions using measured and a synthetic set of optical constants. The results show that tropospheric aerosols consisting of only these organic acids and water have a pure scattering effect.
\end{abstract}

\section{Introduction}

Aerosols have both direct and indirect effects on the Earth's radiative balance and thereby and impact on climate change; currently this impact is associated with a large uncertainty (IPCC, 2001). The direct impact of aerosols on the radiative balance is through the scattering of incoming solar radiation and the absorption of solar and terrestrial radiation which of the processes that dominates depends on the aerosol composition and phase. The aerosols influence the radiative balance indirectly by acting as cloud condensation nuclei and thus affect the cloud microphysics and the albedo of the Earth (IPCC, 2001; Twomey et al., 1984). In a quantification of the aerosol influence on the atmospheric radiative balance, the fundamental parameters to investigate are the optical depth,

Correspondence to: C. J. Nielsen

(claus.nielsen@kjemi.uio.no) $\tau$, and the single scattering albedo, $\varpi$. The optical depth is the extinction resulting from absorption and scattering of radiation by the aerosols in a column and is directly dependant on the aerosol amount. The climate response to $\tau$ is nearly linear for the small optical depths of the greatest interest (Hansen et al., 1997). The spectral characteristics of $\tau$ are required to model the radiative effects of aerosols, to retrieve aerosol parameters from satellite remote sensing, and to correct for aerosol effects in remote sensing of the Earth's surface. In a more detailed understanding of the influence of different aerosol types on the radiative balance, the key parameter is the single scattering albedo, SSA (Hansen et al., 1997). The SSA is determined by the absorption and scattering properties of the aerosol type, the size distribution, and the composition. That is, to calculate the aerosol scattering and absorption one needs the optical constants which is the complex index of refraction, $\tilde{\mathrm{N}}(\lambda)=\mathrm{n}(\lambda)+i \mathrm{k}(\lambda) ; \mathrm{n}(\lambda)$ is the wavelength dependant refractive index, and $\mathrm{k}(\lambda)$ is the corresponding absorption index. At present the data base of complex indices of refraction is very limited, and there is a lack of knowledge on how the different aerosol components influence the Earth's radiative balance.

Tropospheric aerosols are generally complex aqueous mixtures containing numerous different compounds; the major fraction is commonly sulphate and nitrate, however, carbon-containing species may also constitute the dominant fraction. The total carbon fraction (TC) ranges from $0.1 \%-$ $70 \%$ depending on the location, the minimum is found in remote marine areas (Kawamura and Sakaguchi, 1999; Saxena and Hildemann, 1996; Turpin et al., 2000; Zappoli et al., 1999). The characterisation of the carbon-containing fraction is a challenging topic due to the wide range of compounds present. Usually this fraction is divided into a nonwater soluble organic fraction and a water-soluble organic carbon fraction, WSOC. The WSOC may represent up to $75 \%$ of the TC present in aerosols, again, depending on the source and location (Decesari et al., 2001; Kawamura and 
Sakaguchi, 1999; Kiss et al., 2002; Mayol-Bracero et al., 2002; Narukawa et al., 1999; Saxena and Hildemann, 1996).

Mono- and dicarboxylic acids are observed in snow, rain, cloud droplets, fog and aerosols both in urban, rural, marine, remote and polar areas. As a result of the high water affinity and low vapour pressure, dicarboxylic acids accumulate in aerosols (Baboukas et al., 2000; Limbeck et al., 2001). This is in contrast to mono aliphatic carboxylic acids and is supported both by observations and calculations (Chebbi and Carlier, 1996; Saxena and Hildemann, 1996). Dicarboxylic acids account for $1-15 \%$ of the total aerosol carbon (Kawamura and Ikushima, 1993; Kawamura et al., 1996; Sempere and Kawamura, 2003) and exhibit their highest concentrations during periods of increased solar radiation (Kawamura et al., 1995; Sempere and Kawamura, 2003). Organic acids are observed both in the coarse and fine mode, an indication of both primary and secondary sources, respectively (Bardouki et al., 2003; Kavouras and Stephanou, 2002; Neusüss et al., 2000; Yao et al., 2002). The study of Kavouras and Stephanou (2002) showed that in urban aerosols $73.3 \%$ of the dicarboxylic acids are present in the fine mode, $<0.5 \mu \mathrm{m}$, and that no dicarboxylic acids are found in the coarse mode whereas in the marine and particular in forest regions the dicarboxylic acids are also present in the in larger modes.

The widespread presence of the low molecular weight organic acids in the tropospheric particulate matter is explained by the various sources, formation by photochemical reactions, oxidation of anthropogenic as well as natural hydrocarbons and biogenic compounds, and direct emission from combustion engines, meat cooking and biomass combustion (Chebbi and Carlier, 1996; Grosjean et al., 1978; Kawamura and Gagosian, 1987; Kawamura and Ikushima, 1993; Kawamura et al., 1996; Kerminen et al., 2000; Limbeck and Puxbaum, 1999; Rogge et al., 1998; Rogge et al., 1993; Simoneit, 1986). Multiphase/aqueous phase chemistry is also believed to be an important source (Blando and Turpin, 2000; Yao et al., 2002). Blando and Turpin (2000) suggested that there is a potential for secondary aerosol production in clouds. The proposed mechanism is that soluble or partly oxidised gases can be absorbed into water droplets and undergo chemical reactions and result in addition of organic material to the particle phase when the droplet evaporates.

Oxalic acid is the most abundant organic acid in the troposphere at all locations in the continental background aerosols as well as in marine, Antarctic, Arctic, urban areas and in aerosols produced from biomass burning (Grosjean et al., 1978; Kawamura and Ikushima, 1993; Kawamura et al., 1995; Kawamura and Sakaguchi, 1999; Kawamura et al., 1996; Kerminen et al., 2000; Limbeck and Puxbaum, 1999; Mochida et al., 2003; Narukawa et al., 2002; Sempere and Kawamura, 2003). So far, no primary source or gas phase oxidation scheme is known, which results in oxalic acid in the tropospheric aerosols. Instead, aqueous phase chemistry in cloud and fog droplets as well as in aerosols is believed to play an essential role. Subsequent to the aqueous phase production of oxalic acid, the droplets may evaporate and result in aerosols with relatively high concentrations of oxalic acid (Warneck, 2003). The other low molecular weight dicarboxylic acids common in the tropospheric aerosols are malonic $\left(\mathrm{C}_{3}\right)$, succinic $\left(\mathrm{C}_{4}\right)$, glutaric $\left(\mathrm{C}_{5}\right)$, and adipic $\left(\mathrm{C}_{6}\right)$ acid in addition to unsaturated or hydroxylated dicarboxylic acids. Pyruvic, benzoic, phthalic $\left(\mathrm{C}_{8}\right)$ and pinonic acid $\left(\mathrm{C}_{7}\right)$ are also frequently observed (e.g. Bardouki et al., 2003; Limbeck et al., 2001; Sempere and Kawamura, 2003), see Table 1 . The distribution of these organic acids depends on the location: malonic and succinic acid are the most frequently occurring organic acids next to oxalic acid. In the Arctic and Antarctic regions the relative occurrence of phthalic acid is noteworthy higher than elsewhere (Kawamura et al., 1995; Kawamura et al., 1996; Narukawa et al., 2002).

Twomey and co-workers (Twomey et al., 1984) suggested an additional indirect aerosol effect: increased concentrations of atmospheric aerosols will result in higher concentrations of cloud condensations nuclei, $\mathrm{CCN}$, increased cloud droplet concentrations and thereby in smaller droplets. Some organic acids are believed to play an important role as CCN (Cruz and Pandis, 2000; Hori et al., 2003; Limbeck and Puxbaum, 1999; Prenni et al., 2001). Crus and Pandis (2000) showed that above $85 \%$ relative humidity glutaric acid particles take up water, and suggested that glutaric and adipic acid act as efficient CCN. Other studies show that the ability of an organic compound to act as efficient $\mathrm{CCN}$ correlates with its solubility (Corrigan and Novakov, 1999).

The present study addresses a class of compounds present in the WSOC; the $\mathrm{C}_{2}-\mathrm{C}_{6}$ dicarboxylic acids, pyruvic, benzoic, phthalic and pinonic acid, the latter representing the large group of carboxylic acids with a complex structures resulting from the oxidation of terpenes (Jaoui and Kamens, 2003), benzoic and phthalic acid representing the aromatic organic acids present in secondary organic aerosols. We present the absorption index, $\mathrm{k}(\lambda)$, the refractive index, $\mathrm{n}(\lambda)$, and the density of aqueous solutions of the acids. Table 1 summarizes the acids investigated together with the available data of their solubility in water.

\section{Experimental}

\subsection{The absorption index in the ultra violet/visible region}

The experimental method and calculation procedure is reported previously (Myhre et al., 2004) and only the main principles are described here. The spectra were measured at $295 \mathrm{~K}$ in the $200-1100 \mathrm{~nm}$ wavelength range using an Agilent $8454 \mathrm{E}$ photodiode array spectrophotometer with a resolution of $\sim 1 \mathrm{~nm}$, which is sufficient to resolve the expected absorption band structures for the solutions under study, and 
C. E. Lund Myhre and C. J. Nielsen: Optical properties in the UV and visible spectral region

Table 1. Summary of the investigated organic acids and their molecular structures and solubilities in water at $293 \mathrm{~K}$.

\begin{tabular}{cccc}
\hline & $\mathrm{MW}$ & Solubility in water \\
\hline Oxalic acid & & & \\
$\left(\mathrm{C}_{2}\right)$ & 90.03 & &
\end{tabular}

Malonic acid

Glutaric acid

$\left(\mathrm{C}_{5}\right)$

132.11

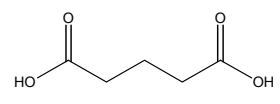

$116 \mathrm{~g}, 63.9 \mathrm{wt} \%$

Pyruvic acid 88.06

Benzoic acid

$\left(\mathrm{C}_{7}\right)$

122.12
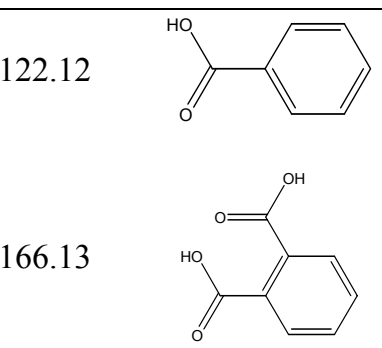

$\left(\mathrm{C}_{8}\right)$

166.13

Phthalic acid

Pinonic acid

$\left(\mathrm{C}_{7}\right)$

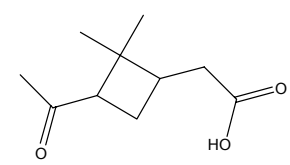

$0.6 \mathrm{~g}$

$0.29 \mathrm{wt} \%$

0.64-0.71

${ }^{a}$ The solubilities in $\mathrm{g} / 100 \mathrm{~g}$ are taken from Saxena and Hildemann (1996) except for pinonic acid, which is taken from Raymond and Pandis (2002).

${ }^{b}$ The solubilities in wt\% is taken from Gerhartz et al. (1985-1996) at $293 \mathrm{~K}$ except for phthalic acid which is taken from Hori et al. (2003). 
Table 2. The investigated binary aqueous samples together with their measured refractive index at $\lambda=632.8 \mathrm{~nm}$ and density at $T=293 \mathrm{~K}$. No data: The $\mathrm{pH}$ was too low to be measured with the available instrument.

\begin{tabular}{|c|c|c|c|c|}
\hline Component & Concentration/wt $\%$ & Refractive index $/ \lambda=633 \mathrm{~nm}$ & Density ${ }^{a} / \mathrm{g} \mathrm{cm}^{-3}$ & $\mathrm{pH}$ \\
\hline \multirow[t]{5}{*}{ Oxalic acid } & 0.01 & 1.3321 & 0.99844 & 3.22 \\
\hline & 0.11 & 1.3322 & 0.99885 & 2.10 \\
\hline & 1.00 & 1.3333 & 1.00329 & 1.75 \\
\hline & 5.05 & 1.3379 & 1.02184 & 1.58 \\
\hline & 10.05 & 1.3428 & no data & 1.10 \\
\hline \multirow[t]{5}{*}{ Malonic acid } & 0.10 & 1.3322 & 0.99847 & 2.53 \\
\hline & 1.04 & 1.3332 & 1.00206 & 2.00 \\
\hline & 9.97 & 1.3428 & 1.03521 & 1.50 \\
\hline & 25.05 & 1.3588 & no data & 1.30 \\
\hline & 60.02 & 1.4031 & no data & 0.80 \\
\hline \multirow[t]{2}{*}{ Hydroxymalonic acid } & 0.01 & 1.3323 & 0.99838 & 2.70 \\
\hline & 1.02 & 1.3335 & 1.00287 & 1.70 \\
\hline \multirow[t]{3}{*}{ Succinic acid } & 0.01 & 1.3323 & 0.99781 & 2.90 \\
\hline & 1.03 & 1.3333 & 1.00102 & 2.70 \\
\hline & 8.07 & 1.3418 & 1.02304 & 1.83 \\
\hline \multirow[t]{5}{*}{ Glutaric acid } & 0.01 & 1.3323 & 0.99839 & 4.00 \\
\hline & 1.03 & 1.3335 & 1.00107 & 2.70 \\
\hline & 4.99 & 1.3379 & 1.01111 & 2.40 \\
\hline & 24.85 & 1.3612 & 1.06383 & 1.92 \\
\hline & 49.96 & 1.3940 & 1.13477 & 1.60 \\
\hline \multirow[t]{3}{*}{ Pyruvic acid } & 0.11 & 1.3324 & 0.99861 & 2.40 \\
\hline & 1.02 & 1.3333 & 1.00192 & 1.90 \\
\hline & 5.01 & 1.3382 & 1.01629 & 1.60 \\
\hline \multirow[t]{3}{*}{ Benzoic acid } & 0.05 & 1.3323 & 0.99838 & 3.20 \\
\hline & 0.10 & 1.3324 & 0.99847 & 3.15 \\
\hline & 0.47 & 1.3328 & 0.99886 & 3.00 \\
\hline \multirow[t]{2}{*}{ Phthalic acid } & 0.07 & 1.3322 & 0.99815 & 2.75 \\
\hline & 0.11 & 1.3326 & 0.99850 & 2.67 \\
\hline cis-Pinonic acid & 0.15 & 1.3324 & 0.99840 & 3.50 \\
\hline
\end{tabular}

${ }^{a}$ The estimated error, $\sigma=0.020$

with an integration time of $0.5 \mathrm{~s}$. The absorption index, $\mathrm{k}(\lambda)$, is derived from the Beer-Lambert law and is given by:

$\mathrm{k}(\lambda)=\ln (10) \frac{\mathrm{A}(\lambda) \cdot \lambda}{4 \pi d}$,

where $\lambda$ is the wavelength, $d$ is the optical path length through the sample, and $\mathrm{A}(\lambda)$ is the dimensionless absorbance, expressed as $-\log \left(\mathrm{I} / \mathrm{I}_{0}\right)$, that is the ratio of the monochromatic radiant power transmitted through the sample to that incident on the sample. The true absorbance cannot be measured directly because the solution to be studied is enclosed by cell windows. Reflection and scattering losses can, and will, occur at the various interfaces of the cell. To compensate for these losses the common procedure in UV/Visible spectroscopy is to use a cell containing only the solute and use this spectrum as $I_{0}(\lambda)$. In the present case this is not an appropriate method as the solvent (water) is an integrated part of the sample and important for the atmospheric application of the results. Instead we employed an alternative method using four cells with closely matching windows but with different path lengths. Assuming that the scattering losses inside the sample can be neglected we may then use the following relation:

$\mathrm{S}_{i}(\lambda)=\operatorname{Rfl}(\lambda)+\mathrm{A}^{\prime}(\lambda) \cdot d_{i}$,

where $\operatorname{Rfl}(\lambda)$ is the reflection loss, $S_{i}(\lambda)$ is the experimental spectrum, $\mathrm{A}^{\prime}(\lambda)$ is the absorbance per unit path length and $d_{i}$ is the corresponding path length of the cell. The absorbance spectrum corrected for the reflection losses, $A(\lambda)$, was obtained by a least square calculation of four spectra with different path lengths. In the present study, the path lengths of the cells were $0.1,0.2,0.5,1.0,2.0,5.0$, and $10.0 \mathrm{~mm}$; the selection of the 4 most appropriate path lengths was determined by the absorption strength. The absorbance spectrum corrected for the reflection losses, $\mathrm{A}(\lambda)$, is in turn used in Eq. (1) to derive the absorption index, $\mathrm{k}(\lambda)$.

A critical point in the analysis is the assumption that the scattering losses inside the sample can be neglected, and that only the reflection losses at the windows are contributing to 
$\operatorname{Rfl}(\lambda)$ in Eq. (2). We have previously justified this assumption, carried out a critical evaluation of the error in the absorption index in the UV/VIS wavelength region derived by this procedure, and tested our method by comparison with literature data of absorption indexes (Myhre et al., 2004). The agreement with absorption index of water presented by Bertie and Lan (1996) is quite satisfactory - the difference is less than 1 standard error of the least squares fit, and a maximum absolute difference at $990 \mathrm{~nm}$ of less than $1.0 \times$ $10^{-7}$. We have also compared our results obtained for 25 wt $\%$ aqueous $\left(\mathrm{NH}_{4}\right)_{2} \mathrm{SO}_{4}$ and $48 \mathrm{wt} \%$ aqueous $\mathrm{H}_{2} \mathrm{SO}_{4}$ with data from Gosse et al. (1997) and obtained a similar agreement. The differences are less than $2 \%$ in the absorbing regions and less than $10 \%$ in non-absorbing regions.

Based on this examination we estimate that the relative uncertainty in the reported absorption indexes is less than 5\% in regions with absorption indexes higher than $1.0 \times 10^{-6}$. The photometric noise in our instrument results in a relative uncertainty below $1 \%$ when the absorption index is higher than $5.0 \times 10^{-7}$. The uncertainty in the path lengths of the cells are $\pm 0.01 \mathrm{~mm}$ resulting in an relative uncertainty in absorption index of less than $\sim 1 \%$ except for oxalic and benzoic acid where the shortest cells are applied. The shortest cells results in an relative uncertainty of $\sim 2 \%$ when the absorption index is higher than $\sim 5.0 \times 10^{-6}$ and increase to about $10 \%$ when $\mathrm{k}(\lambda)$ is around $1.0 \times 10^{-7}$.

\subsection{The refractive index and the calculation procedure}

The refractive index of the aqueous organic acids were measured at $\lambda=632.8 \mathrm{~nm}\left(15798 \mathrm{~cm}^{-1}\right.$, He-Ne laser $)$ using a thermostated Abbe Standard 60 refractometer and keeping the temperature at $293 \pm 0.5 \mathrm{~K}$. The refractive index at each concentration reported in Table 2 results from an average of 4 individual measurements, all with standard deviations less than $2 \times 10^{-4}$. The estimated absolute error $(1 \sigma)$ of approximately $0.15 \%$ is based on the instrument ability to reproduce literature values at the relevant wavelength and temperature.

The wavelength dependant refractive index, $n(\lambda)$, in the region from 275-1100 nm was determined from the absorption index by the Kramer-Kronig relation as described by Ohta and Ishida (1988) and Bertie et al. (1993), and using the measured index of refraction at $632.8 \mathrm{~nm}$ as anchor point.

\subsection{The density}

The density was measured by the use of a Density/Specific Gravity/Concentration Meter, DMA 5000, from Anton Paar. The repeatability of the instrument is reported to be $1 \times 10^{-6} \mathrm{~g} \mathrm{~cm}^{-3}$ and the temperature is controlled to $\pm 0.001 \mathrm{~K}$. All measurements were performed at $T=293.00 \mathrm{~K}$. The measuring range of the instrument is from $0-3 \mathrm{~g} \mathrm{~cm}^{-3}$ and the approximate amount of sample in the measuring cell is $1 \mathrm{~mL}$. The uncertainty in our reported den- sity data is estimated to $\pm 4 \times 10^{-4} \mathrm{~g} \mathrm{~cm}^{-3}$ determined by the uncertainty in the concentrations.

\section{Results and discussion}

The concentrations of the organic acids in the ambient aerosols are determined by several factors, among them are the relative humidity and their vapour pressure. To cover a wide range of conditions we have investigated the aqueous organic acids at different concentrations spanning from highly diluted samples, representing fog and cloud conditions, to concentrations close to saturation, representing the conditions of aerosols at low relative humidity.

\subsection{The density of aqueous organic acids}

The density is an essential quantity in modelling the complex index of refraction of multi-component solutions. We only measured the density of samples having a $\mathrm{pH}$ higher than approximately $1.6-$ a restriction emerged by the instrument. The results of the density measurements are listed in Table 2. Relatively small variations in the density were registered even for the solutions with highest concentrations. The density of all the investigated samples is ranging from the value of water at $293 \mathrm{~K}, 0.99824 \mathrm{~g} \mathrm{~cm}^{-3}$ at $1 \mathrm{~atm}$ (Lemmon et al., 2003) to that of a 50 mass weight percent (wt\%) glutaric acid with a density of $1.1348 \mathrm{~g} \mathrm{~cm}^{-3}$. In the investigated concentration range the measured densities are reasonably approximated by a simple relation:

$\rho_{\text {solution }}=0.99824+0.708 \cdot x^{0.771}$,

where $x$ is the mole fraction acid in the solution. This empirical relation reproduces all the observations within $0.0013 \mathrm{~g} \mathrm{~cm}^{-3}$, which should be compared to the estimated uncertainty of $0.0004 \mathrm{~g} \mathrm{~cm}^{-3}$. That is the empirical relation reproduces the observation within 3 times the estimated standard deviation of the observations.

\subsection{The absorption index of aqueous organic acids}

The spectral structures of the UV/VIS absorption indices of the aliphatic dicarboxylic acids are very similar. The band observed in the spectra is the weak $\pi^{*} \leftarrow \mathrm{n}$ transition of the carboxylic group and for oxalic acid it is known to start close to $\sim 300 \mathrm{~nm}$ with its maximum around $260 \mathrm{~nm}$ in aqueous solutions (Back, 1984; Maria and McGlynn, 1972); the band is shifted towards lower wavelengths in aqueous polar solutions compared with the vapour phase (Back, 1984; Martin et al., 2000). The medium-strong $\pi^{*} \leftarrow \pi$ transition occurs in the vacuum UV around $170 \mathrm{~nm}$. In the investigated samples the band centres are slightly displaced due to conjugation, substitution and solvent effects. Figure 1 shows the absorbance in the UV-Visible region of 4 selected organic acids dissolved in water. The aromatic compounds presented in the upper panel exhibit the $\pi^{*} \leftarrow \pi$ transition typical for aromatic rings 


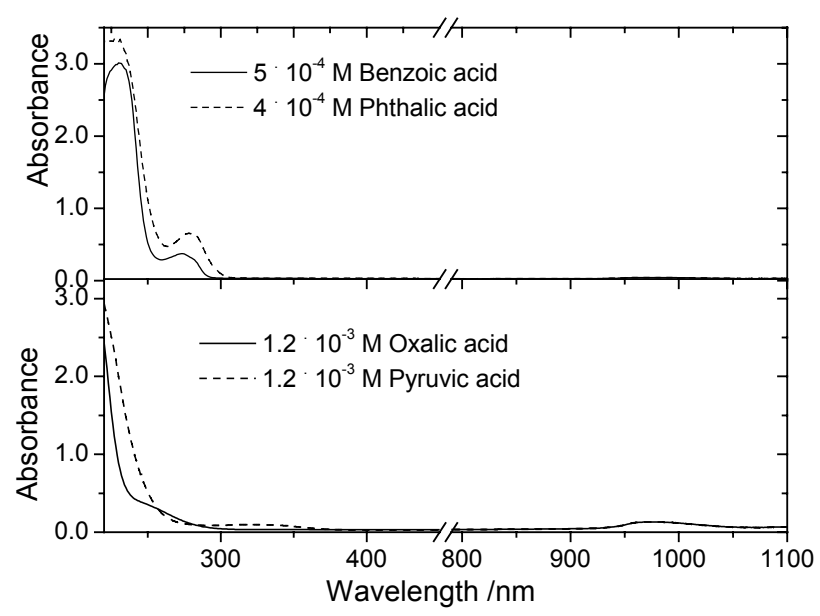

Fig. 1. The absorbance spectra of selected organic acids in the UV/VIS region. The concentrations are in molar.

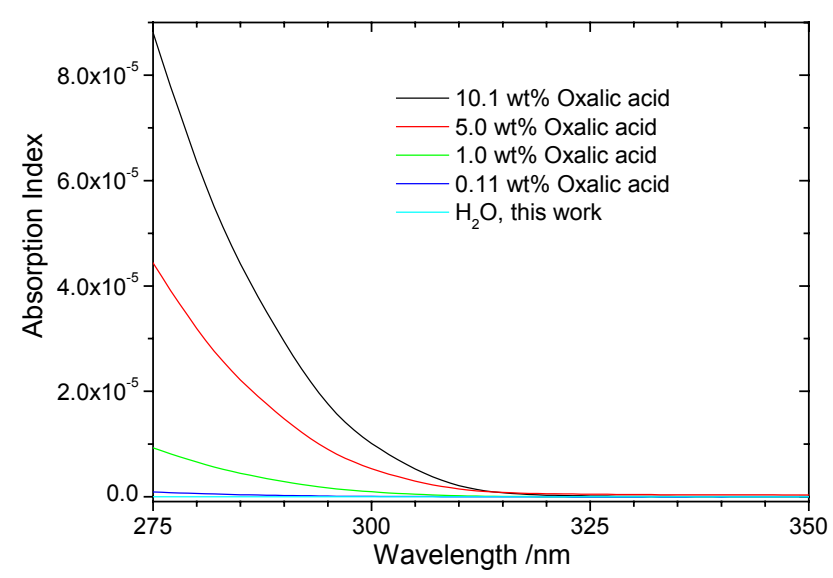

Fig. 2. The absorption index of oxalic acid in the UV-region. Data for water is included for comparison.

in addition to the carbonyl transition $\pi^{*} \leftarrow \mathrm{n}$ at $\sim 275 \mathrm{~nm}$ (the path length used in the presented absorbance spectra of the aromatic compounds is $1 \mathrm{~mm}$ ). The results demonstrate that the absorbance in the visible and near infrared region is dominated by the weak water overtone/combination band around $980 \mathrm{~nm}$, whereas in the in UV region large differences are evident. In the lower panel are the absorbance spectra of oxalic and pyruvic acid in $5 \mathrm{~mm}$ cells presented. The spectral positions of the bands observed for oxalic acid and the other investigated dicarboxylic acids are very similar, but pyruvic acid differs being a keto acid, see Table 1 , with its $\pi^{*} \leftarrow \mathrm{n}$ transition of the keto group around $325 \mathrm{~nm}$.

The spectral characteristics of the absorption index of oxalic acid are further visualized in Fig. 2, which shows the absorption index of oxalic acid at different concentrations in the $275-400 \mathrm{~nm}$ spectral region. The figure illustrates that in

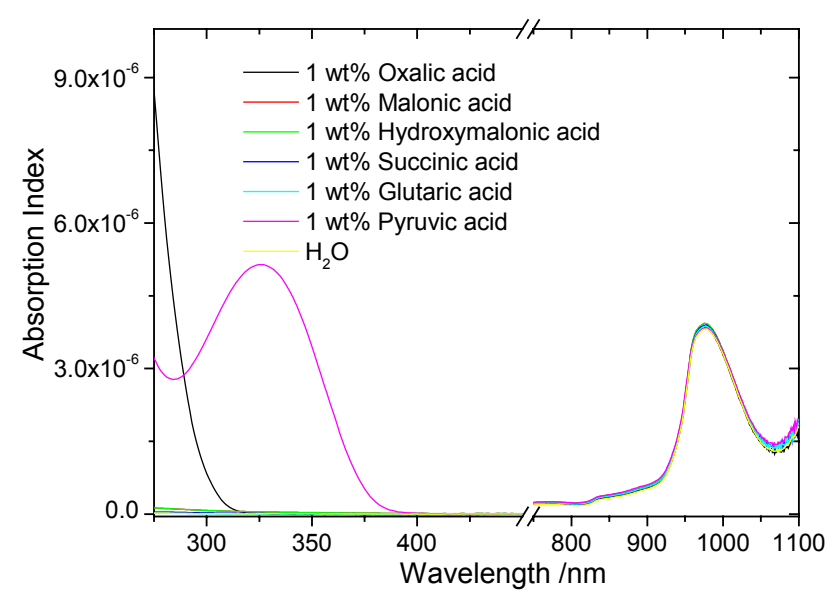

Fig. 3. The absorption index of the selected $1 \mathrm{wt} \%$ dicarboxylic acids and pyruvic acid. The absorption index of water is included for comparison.

this wavelength region the absorption index is linearly dependant on the molar concentration of oxalic acid, and molecular interactions and dissociation do not influence this part of the spectrum. This is in agreement with the UV spectra obtained of different oxalate species (Cruywagen and Heyns, 1983). Note that even though the $\pi^{*} \leftarrow \mathrm{n}$ transition in oxalic acid is weak, the absorption index of a $1 \mathrm{wt} \%$ oxalic acid is approximately a factor of 100 larger than that of water at $300 \mathrm{~nm}$. The results for oxalic acid are representative for all the aliphatic dicarboxylic acids, the only difference being that the longer dicarboxylic acids show much weaker band intensities in this region. Figure 3 compares the absorption index of oxalic, malonic, hydroxymalonic, succinic, glutaric and pyruvic acid at $1 \mathrm{wt} \%$. The intensity difference between oxalic acid and the other acids investigated is substantial. It is worth to emphasize that the absorption indexes of hydroxymalonic acid and malonic acid are nearly identical in the entire wavelength region demonstrating that the $\alpha$-hydroxyl group does not influence the absorption index in a significant manner. Furthermore the figure clearly illustrates the different spectral profile of pyruvic acid, discussed previously.

The band in the near infrared region, located around $975 \mathrm{~nm}$ is an infrared water overtone/combination band and the absorption strength is dependant on the amount of water present in the investigated samples. Accordingly, the absorption index of this band is identical for all the $1 \mathrm{wt} \%$ organic acids and for concentrations in this range, also identical with that of pure water. The absorption index of this band decreases in the highly concentrated solutions. This is demonstrated in Fig. 4, which shows the absorption index of glutaric acid at 3 concentrations; 1,25 and $50 \mathrm{wt} \%$. The intensity of the water band is reduced as the concentration of the dicarboxylic acid increase. However in contrast to the almost perfectly linear relationship between the absorption in the UV/VIS region and the molar concentration, the relationship 


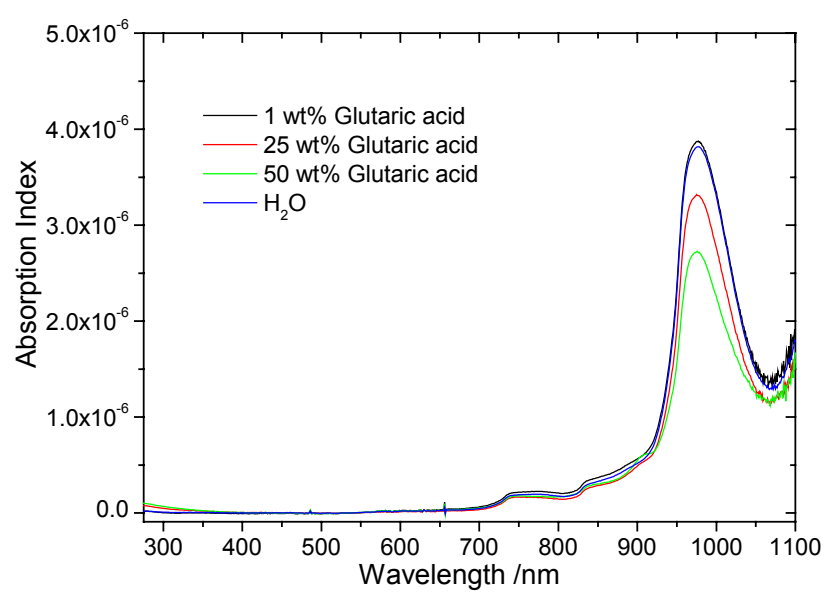

Fig. 4. The absorption index of glutaric acid at different concentrations. Data for water is included for comparison.

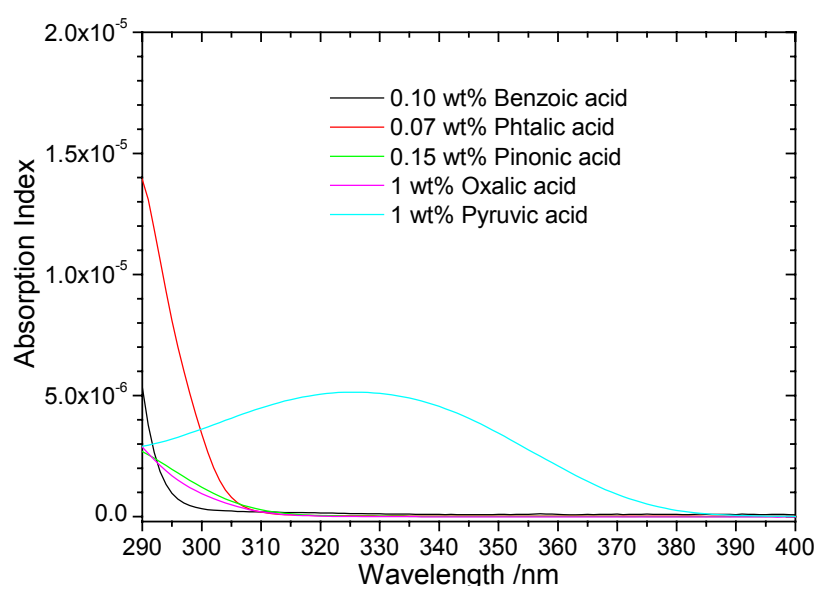

Fig. 5. Comparison of the absorption index of selected organic acids in the UV-region.

of this band deviates slightly from linearity. As mentioned this band originates from the overtones and combinations of infrared bands and generally intermolecular forces are essential for the structure of overtone and combination bands of aqueous solutions. The UV/VIS spectrum of glutaric acid, $\mathrm{C}_{5}$, is very weak at wavelengths longer than $275 \mathrm{~nm}$, and essentially comparable to water, also for the $50 \mathrm{wt} \%$ glutaric acid.

A comparison of the selected organic acids investigated is presented in Fig. 5. The results demonstrate that the absorption by the aromatic compounds is much stronger than for the cyclic and aliphatic acids and phthalic acid is the one with the highest absorption investigated in this wavelength region. Pinonic acid, the cyclic dicarboxylic acid, has comparable absorption strength to the aliphatic dicarboxylic acids; still the absorption index of this compound is somewhat stronger than oxalic acid at the same concentration. Again we observe the different profile of the absorption spectrum of pyruvic

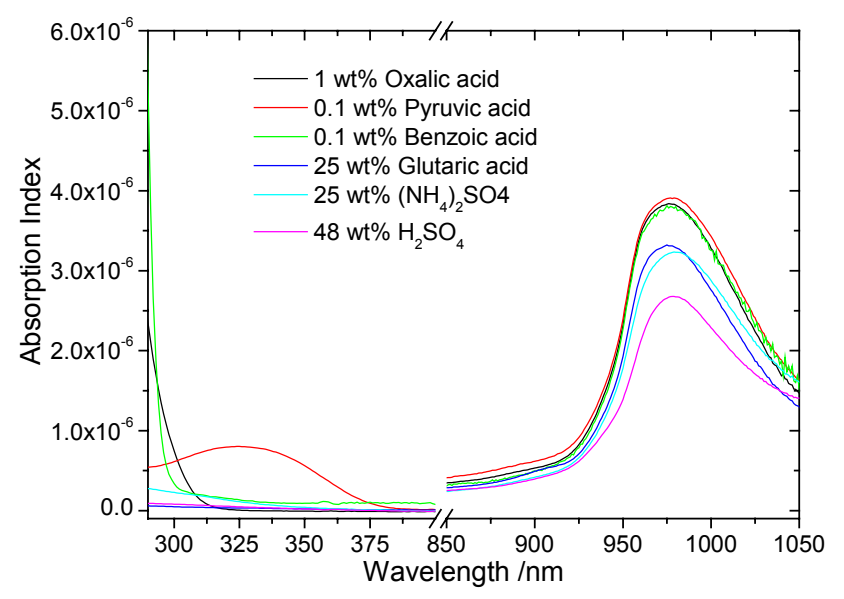

Fig. 6. The absorption index of selected organic acids compared with common inorganic aerosol components.

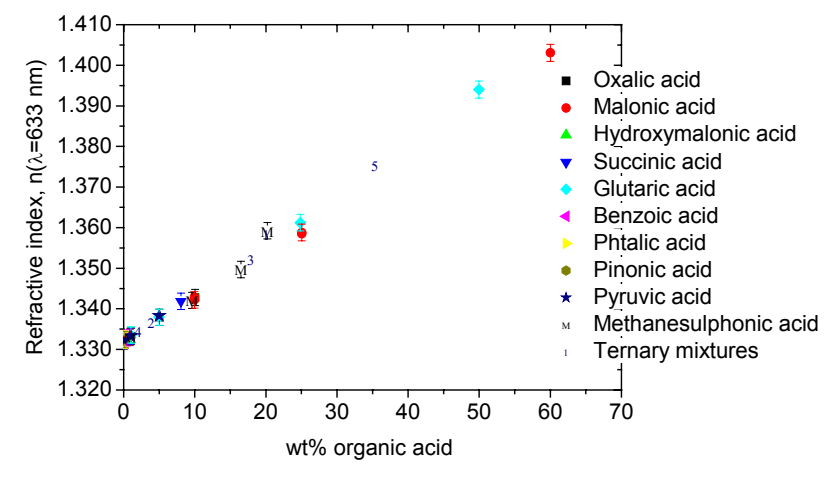

Fig. 7. The refractive index at $\lambda=633$ of binary and ternary mixtures of organic acids dissolved in water at different concentrations. The data for aqueous methanesulphonic acid (M) were not included in the least squares fitting according to Eq. (4).

acid with a band centre at $325 \mathrm{~nm}$. This displacement may be of atmospheric importance and is further investigated in the calculations of the single scattering albedo.

Figure 6 illustrates a comparison of some of the investigated water-soluble organic acids together with common inorganic aerosol species and water. In the UV/VIS region above $275 \mathrm{~nm}$ there are very weak absorbances for all the compounds with pyruvic acid as the most interesting for atmospheric applications. In the near infrared region is it the amount of water, which is totally determining the intensity. This is clearly illustrated by the results of aqueous $25 \mathrm{wt} \%$ glutaric acid and aqueous $25 \mathrm{wt} \%\left(\mathrm{NH}_{4}\right)_{2} \mathrm{SO}_{4}$, which is virtually equal and only minor changes are apparent possibly explained by different intermolecular forces.

\subsection{The refractive index of aqueous organic acids}

Table 2 presents the results of the refractive index measurements at $\lambda=632.8 \mathrm{~nm}$, and the results are visualised in Fig. 7 
Table 3. Mixtures used in the experimental tests of the mixing model together with their measured refractive index and density at $T=293 \mathrm{~K}$.

\begin{tabular}{ccccc}
\hline $\mathrm{Nr}$ & Component i & Component $\mathrm{j}$ & Refractive index $\lambda=632.8 \mathrm{~nm}$ & Density $/ \mathrm{g} \mathrm{cm}^{-3}$ \\
\hline 1 & $10 \mathrm{wt} \%$ malonic acid & $10 \mathrm{wt} \%\left(\mathrm{NH}_{4}\right)_{2} \mathrm{SO}_{4}$ & 1.3585 & 1.09249 \\
2 & $2 \mathrm{wt} \%$ oxalic acid & $2 \mathrm{wt} \%$ succinic acid & 1.3368 & no data \\
3 & $10.5 \mathrm{wt} \%$ oxalic acid & 7.5 succinic acid & 1.3523 & no data \\
4 & $1 \mathrm{wt} \%$ oxalic acid & $1 \mathrm{wt} \%$ glutaric acid & 1.3346 & 1.00619 \\
5 & $4.5 \mathrm{wt} \%$ oxalic acid & $31.5 \mathrm{wt} \%$ succinic acid & 1.3753 & no data \\
\hline
\end{tabular}

where the results for the ternary mixtures are indicated by their numbers in Table 3. As can be seen the refractive index of the aqueous organic acids is essentially determined by the amount acid present, and not by the molecular characteristics of the components. The refractive index changes linearly with the total acid weight percent in the investigated concentration range from 0 to $60 \mathrm{wt} \%$. We have recently reported refractive index of aqueous methanesulphonic acid solutions (Myhre et al., 2004), and these data, indicated by " $M$ " in Fig. 7, fit very well with the dependence of the refractive index on the total solute concentration present in the sample.

The refractive index at $\lambda=632.8 \mathrm{~nm}$ of binary as well as general mixtures can quite accurately be approximated by a polynomial in the acid weight fraction, $w$, in region from 0 to 0.6 :

$n_{\lambda=632.8}=1.3320+0.12 \cdot w$.

This empirical relation reproduces all the observations (for the organic acids) within 0.0005 , which should be compared to the estimated uncertainty of 0.0002 . That is the empirical relation reproduces the observation within 3 times the estimated standard deviation of the observations.

\subsection{Experimental and parameterised absorption and refrac-} tive index of organic aqueous mixtures

The absorption index of mixtures of different organic and inorganic compounds is of particular importance in atmospheric research. Our results of the binary mixtures of pure organic acids dissolved in water indicate that the absorption index in the $280-1050 \mathrm{~nm}$ region is directly proportional to the molar concentrations of the acid and water. The only minor deviation being the water overtone/combination band around $980 \mathrm{~nm}$, see Sect. 3.2. We have also investigated selected ternary mixtures to examine if the absorption index of these types of mixtures might show the same simple linear molar concentration relationship.

The ternary mixtures investigated in this work span a wide range of conditions, from diluted solutions to solutions close to saturation. The mixtures are also composed according to their solubilities with oxalic acid mixed both with a highly soluble dicarboxylic acid, glutaric acid, and with a lesser soluble acid. We have also studied a mixture of an inorganic salt, $\left(\mathrm{NH}_{4}\right)_{2} \mathrm{SO}_{4}$, together with malonic acid. Table 3 summarises the mixtures investigated together with their measured densities and refractive indexes at $\lambda=632.8 \mathrm{~nm}$.

The absorption index of the ternary mixtures can be calculated from the absorption indices of the individual components by a simple linear parameterisation:

$k_{i, j, w}^{t}\left(M_{i}, M_{j}, M_{w}\right)=M_{i} \cdot k_{i}^{b}(\lambda)+M_{j} \cdot k_{j}^{b}(\lambda)+M_{w} \cdot k_{w}(\lambda)$,

where $k_{i, j, w}^{t}(\lambda)$ is the absorption index of a ternary mixture, $M_{i}$ and $M_{j}$ are the molar concentrations of component $i$ and $j$ dissolved in water, and $M_{w}$ is the molar concentration of water. $k_{i}^{b}(\lambda)$ and $k_{j}^{b}(\lambda)$ are the molar absorption index component $i$ and $j$, respectively, and $k_{w}(\lambda)$ is the molar absorption index of pure water. The molar absorption indexes of the acids studied and of pure water are given as supplementary information. The experimental absorption index of the mixtures are reproduced within $1 \times 10^{-6}$ in the UV region, while the deviations are somewhat larger in the near infrared region when the absorption features are of vibrational origin.

The results of this exercise shows that provided the molecular interactions do not change substantially with mixing, one may estimate the absorption index of any mixture of the organic acids quite accurately by:

$k_{i, j, k, l, \ldots, w}^{t}\left(M_{i}, M_{j}, M_{k}, M_{l}, \ldots, M_{w}\right)$

$=M_{w} \cdot k_{w}(\lambda)+\sum_{i} M_{i} \cdot k_{i}^{b}(\lambda)$

also given as supplementary information. The corresponding refractive index $n_{\lambda=632.8}$ of the mixture may in turn be calculated from Eq. (4). Finally, $n(\lambda)$ of a mixture can then be obtained by the Kramers-Kronig transformation of the calculated absorption index employing $n_{\lambda=632.8}$ as the anchor point.

3.5 Single scattering albedo of aqueous organic acids aerosols

The single scattering albedo, SSA, is defined as:

$\varpi=\frac{Q_{\text {scat }}}{Q_{\text {scat }}+Q_{\text {abs }}}$,

where $Q_{\text {scat }}$ is the scattering efficiency and $Q_{\text {abs }}$ is the absorption efficiency of the aerosols calculated by Mie theory 
assuming spherical particles and adopting the aerosol complex index of refraction and size distribution. The interpretation of SSA is that for $\varpi=1$ the aerosols in question are totally scattering and therefore lower the global mean surface temperature; low values of $\varpi$ indicate that the aerosols will rise the global mean surface temperature. Several climate and radiative model studies have investigated the turnover value. Haywood and Shine (1995) showed that the critical value of SSA changes as a function of the surface reflectance. With the global mean albedo of 0.3 as the chosen surface reflectance they reported the critical single scattering albedo to be approximately 0.85 , dependant on the size of the aerosol. Later Hansen et al. (1997) reported critical values in the range from 0.86-0.91. The highest value represents a model case when all feedback mechanisms are included, inclusive the effect of absorbing aerosol on clouds, referred to as the semidirect aerosol effect. Hansen et al. (1997) concluded that aerosols with single scattering albedo as large as $\varpi=0.9$ might lead to net global warming, and that the anthropogenic aerosol feedback on the global mean surface temperature might be positive.

Calculations of the single scattering albedo using the obtained complex index of refraction of different mixtures were performed. A model using Mie theory assuming spherical aerosols is applied (Wiscomb, 1980). To study the effect of various optical constants of organic acids we have assumed constant aerosol distribution in all the calculations. Size distributions may vary considerably for organic aerosols as the sizes of the aerosols are dependant on factors as primary or secondary sources and the aging of the aerosols. Yao et al. (2002) presented size distributions of aerosols containing dicarboxylic acids and they find that the profile of the size distributions of these aerosols is similar to the profile of the size distribution of sulphate aerosols. However, they found that most of the dicarboxylic acids were observed in a mode with radii ranging from $0.16-0.5 \mu \mathrm{m}$, and not in the accumulation mode. This is in contrast to the observations of Kavouras and Stephanou (2002). We therefore investigated two cases with different geometric mean radii. A mono lognormal size distribution with and standard geometric mean of 2.0 is used and the geometric mean radius of $0.05 \mu \mathrm{m}$ is applied as a typical value for the fine mode and a radius of $0.25 \mu \mathrm{m}$ as a representative value from the study of Yao et al. (2002). The results are presented in Fig. 8. The upper panels (a) and (b) show the calculated refractive and absorption index respectively of the mixture with the highest organic content investigated; $5 \mathrm{wt} \%$ oxalic acid, $5 \mathrm{wt} \%$ malonic acid, $5 \mathrm{wt} \%$ succinic acid, $5 \mathrm{wt} \%$ glutaric acid, $20 \mathrm{wt} \%$ pyruvic acid, $1 \mathrm{wt} \%$ benzoic acid $\mathrm{H}_{2} \mathrm{O}$; a total organic content of $41 \mathrm{wt} \%$. The absorption and refractive indices are calculated using the presented parameterisation and procedure. The lower panel shows the calculated single scattering albedo for the two cases. The red curve is the SSA using $r=0.05 \mu \mathrm{m}$ as the radius and the black curve is the results corresponding to $r=0.25 \mu \mathrm{m}$. The lowest SSA value calculated

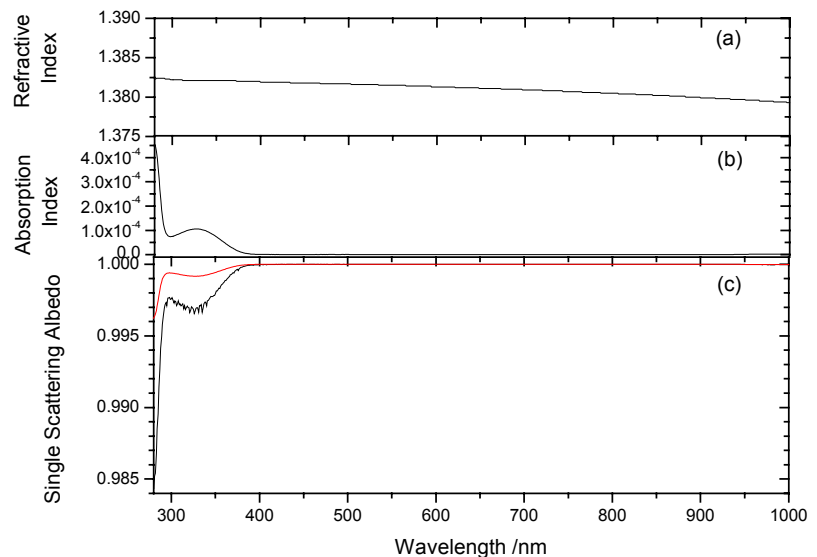

Fig. 8. Optical properties of a mixture consisting of $5 \mathrm{wt} \%$ oxalic acid, $5 \mathrm{wt} \%$ malonic acid, $5 \mathrm{wt} \%$ succinic acid, $5 \mathrm{wt} \%$ glutaric acid, $20 \mathrm{wt} \%$ pyruvic acid, $1 \mathrm{wt} \%$ benzoic acid and $\mathrm{H}_{2} \mathrm{O}$. The refractive and absorption index presented in (a) and (b) respectively is calculated by use of the presented parameterisation. The single scattering albedo presented in (c) is for two different size distributions; red curve $r=0.05 \mu \mathrm{m}$, black curve $r=0.25 \mu \mathrm{m}$.

is 0.996 at $325 \mathrm{~nm}$ and a geometric mean radius of $0.25 \mu \mathrm{m}$. The minimum value is results from the absorption band of $20 \mathrm{wt} \%$ pyruvic acid.

\section{Atmospheric implications and conclusions}

The conclusion from the SSA calculations is that tropospheric aerosols consisting of organic acids and water, similar to the ones studied here, have a pure scattering effect. These classes of organic compounds present in aerosols scatter solar radiation similar to sulphate aerosols and have a cooling effect on the climate; these aerosols do not have a direct aerosol heating potential. The conclusion is not dependant on the concentration of the organic acids present in the aerosols. Pyruvic acid is the only investigated acid with absorption band in the wavelength range from $300-700 \mathrm{~nm}$. The results show that even if the aerosols contain $75 \mathrm{wt} \%$ of pyruvic acid the absorption is still too weak and taking place at too short wavelengths to have any possibility to rise the global mean temperature.

\section{Supplementary material available.}

Acknowledgements. The present work was funded through the Norwegian Research Council Grant no. 123289/410.

Edited by: W. Conant 


\section{References}

Baboukas, E. D., Kanakidou, M., and Mihalopoulos, N.: Carboxylic acids in gas and particulate phase above the Atlantic Ocean, J. Geophys. Res. A, 105, D11, 14 459-14 471, 2000.

Back, R. A.: The ultraviolet absorption spectrum of oxalic acid vapor, Can. J. Chem., 62, 8, 1414-1428, 1984.

Bardouki, H., Liakakou, H., Economou, C., Sciare, J., Smolik, J., Zdimal, V., Eleftheriadis, K., Lazaridis, M., Dye, C., and Mihalopoulos, N.: Chemical composition of size-resolved atmospheric aerosols in the eastern Mediterranean during summer and winter, Atmos. Env., 37, 2, 195-208, 2003.

Bertie, J. E., Zhang, S. L., Eysel, H. H., Baluja, S., and Ahmed, M. K.: Infrared intensities of liquids. XI: infrared refractive indices from 8000 to $2 \mathrm{~cm}^{-1}$, absolute integrated intensities, and dipole moment derivatives of methanol at $25^{\circ} \mathrm{C}$, Appl. Spec., 47 , 8, 1100-1114, 1993.

Blando, J. D. and Turpin, B. J.: Secondary organic aerosol formation in cloud and fog droplets: a literature evaluation of plausibility., Atmos. Envir., 34, 10, 1623-1632, 2000.

Chebbi, A. and Carlier, P.: Carboxylic acids in the troposphere, occurrence, sources, and sinks: a review, Atmos. Envir., 30, 24, 4233-4249, 1996.

Corrigan, C. E. and Novakov, T.: Cloud condensation nucleus activity of organic compounds: a laboratory study, Atmos. Envir., 33, 17, 2661-2668, 1999.

Cruywagen, J. J. and Heyns, J. B. B.: Determination of the dissociation constants of oxalic acid and the ultraviolet spectra of the oxalate species in $3 \mathrm{M}$ perchlorate medium, Talanta, 30, 3, 197200, 1983.

Cruz, C. N. and Pandis, S. N.: Deliquescence and Hygroscopic Growth of Mixed Inorganic-Organic Atmospheric Aerosol, Environmental Science and Technology, 34, 20, 4313-4319, 2000.

Decesari, S., Facchini, M. C., Matta, E., Lettini, F., Mircea, M., Fuzzi, S., Tagliavini, E., and Putaud, J.-P.: Chemical features and seasonal variation of fine aerosol water-soluble organic compounds in the Po Valley, Italy, Atmos. Envir., 35, 21, 3691-3699, 2001.

Gerhartz, W., Elvers, B., Yamamoto, S., Campbell, T., Pfefferkorn, R., Rounsaville, J., and Editors: Ullmann's Encyclopedia of Industrial Chemistry: Fifth, Completely Revised Edition, Weinheim: VCH Verlagsgesellschaft, 1985-1996.

Gosse, S. F., Wang, M., Labrie, D., and Chylek, P.: Imaginary part of the refractive index of sulfates and nitrates in the $0.7-2.6 \mu \mathrm{m}$ spectral region, Appl. Opt., 36, 16, 3622-3634, 1997.

Grosjean, D., Van Cauwenberghe, K., Schmid, J. P., Kelley, P. E., and Pitts Jr., J. N.: Identification of $\mathrm{C}_{3}-\mathrm{C}_{10}$ aliphatic dicarboxylic acids in airborne particulate matter, Env. Sc. Tec., 12, 3, 313-317, 1978.

Hansen, J., Sato, M., and Ruedy, R.: Radiative forcing and climate response, J. Geophys. Res. A, 102, D6, 6831-6864, 1997.

Haywood, J. M. and Shine, K. P.: The effect of anthropogenic sulfate and soot aerosol on the clear sky planetary radiation budget, Geophys. Res. Lett., 22, 5, 603-606, 1995.

Hori, M., Ohta, S., Murao, N., and Yamagata, S.: Activation capability of water soluble organic substances as CCN, J. Aero. Sc., 34, 4, 419-448, 2003.

IPCC: Climate Change 2001: The Scientific Basis. Contribution of Working Group I to the Third Assessment Report of the Intergovernmental Panel on Climate Change, edited by Houghton, J.
T., Ding, Y., Griggs, D. J., Noguer, M., van der Linden, P. J., Dai, X., Maskell, K., and Johnson, C. A., Cambridge University Press, Cambridge, United Kingdom and New York, NY, USA, 2001.

Jaoui, M. and Kamens, R. M.: Gaseous and particulate oxidation products analysis of a mixture of $\alpha$-pinene $+\beta$-pinene $/ \mathrm{O}_{3} /$ air in the absence of light and $\alpha$-pinene $+\beta$-pinene $/ \mathrm{NO}_{\mathrm{x}} /$ air in the presence of natural sunlight, J. Atmos. Chem., 44, 3, 259-297, 2003.

Kavouras, I. G., and Stephanou, E. G.: Particle size distribution of organic primary and secondary aerosol constituents in urban, background marine, and forest atmosphere, J. Geophys. Res. A., 107, D7 and D8, AAC 7/1-AAC 7/13, 2002.

Kawamura, K. and Gagosian, R. B.: Implications of woxocarboxylic acids in the remote marine atmosphere for photooxidation of unsaturated fatty acids, Nature (London, United Kingdom), 325, 6102, 330-332, 1987.

Kawamura, K. and Ikushima, K.: Seasonal changes in the distribution of dicarboxylic acids in the urban atmosphere, Env. Sc. Tec., 27, 10, 2227-2235, 1993.

Kawamura, K., Kasukabe, H., Yasui, O., and Barrie, L. A.: Production of dicarboxylic acids in the arctic atmosphere at polar sunrise, Geophys. Res. Lett., 22, 10, 1253-1256, 1995.

Kawamura, K. and Sakaguchi, F.: Molecular distributions of water soluble dicarboxylic acids in marine aerosols over the Pacific Ocean including tropics, J. Geophys. Res. A, 104, D3, 35013509, 1999.

Kawamura, K., Semere, R., Imai, Y., Fujii, Y., and Hayashi, M.: Water soluble dicarboxylic acids and related compounds in Antarctic aerosols, J. Geophys. Res. A, 101, D13, 18721$18728,1996$.

Kerminen, V.-M., Ojanen, C., Pakkanen, T., Hillamo, R., Aurela, M., and Merilainen, J.: Low-molecular-weight dicarboxylic acids in an urban and rural atmosphere, J. Aero. Sci., 31, 3, 349362, 2000.

Kiss, G., Varga, B., Galambos, I., and Ganszky, I.: Characterization of water-soluble organic matter isolated from atmospheric fine aerosol, J. Geophys. Res. A, 107, D21, ICC1/1-ICC1/8, 2002.

Lemmon, E. W., McLinden, M. O., and Friend, D. G.: Thermophysical Properties of Fluid Systems, National Institute of Standards and Technology, Gaithersburg MD, 20899, 2003.

Limbeck, A. and Puxbaum, H.: Organic acids in continental background aerosols, Atmos. Env., 33, 12, 1847-1852, 1999.

Limbeck, A., Puxbaum, H., Otter, L., and Scholes, M. C.: Semivolatile behavior of dicarboxylic acids and other polar organic species at a rural background site (Nylsvley, RSA), Atmos. Envir., 35, 10, 1853-1862, 2001.

Maria, H. J. and McGlynn, S. P.: Electronic states of oxalic acid and dimethyloxalate. Absorption studies, J. Mol. Spectr., 42, 1, 177-196, 1972.

Martin, M. E., Sanchez, M. L., Olivares del Valle, F. J., and Aguilar, M. A.: A multiconfiguration self-consistent field/molecular dynamics study of the $\left(n->p^{*}\right)^{1}$ transition of carbonyl compounds in liquid water, J. Chem. Phys., 113, 15, 6308-6315, 2000.

Mayol-Bracero, O. L., Guyon, P., Graham, B., Roberts, G., Andreae, M. O., Decesari, S., Facchini, M. C., Fuzzi, S., and Artaxo, P.: Water-soluble organic compounds in biomass burning aerosols over Amazonia 2. Apportionment of the chemical composition and importance of the polyacidic fraction, J. Geophys. Res. A, 107, D20, LBA59/1-LBA59/15, 2002. 
Mochida, M., Kawabata, A., Kawamura, K., Hatsushika, H., and Yamazaki, K.: Seasonal variation and origins of dicarboxylic acids in the marine atmosphere over the western North Pacific, J. Geophys. Res. A., 108, D6, AAC7/1-AAC7/11, 2003.

Myhre, C. E. L., D’Anna, B., Nicolaisen, F. M., and Nielsen, C. J.: Properties of Aqueous Methanesulphonic Acid: Complex Index of Refraction and Surface Tension, Appl. Opt., 43, 12, 25002509, 2004.

Narukawa, M., Kawamura, K., Li, S. M., and Bottenheim, J. W.: Dicarboxylic acids in the Arctic aerosols and snowpacks collected during ALERT 2000, Atmos. Envir., 36, 15-16, 24912499, 2002.

Narukawa, M., Kawamura, K., Takeuchi, N., and Nakajima, T.: Distribution of dicarboxylic acids and carbon isotopic compositions in aerosols from 1997 Indonesian forest fires, Geophys. Res. Lett., 26, 20, 3101-3104, 1999.

Neusüss, C., Pelzing, M., Plewka, A., and Herrmann, H.: A new analytical approach for size-resolved speciation of organic compounds in atmospheric aerosol particles: methods and first results, J. Geophys. Res. A., 105, D4, 4513-4527, 2000.

Ohta, K. and Ishida, H.: Comparison among several numerical integration methods for Kramers-Kronig transformation, Appl. Spectr., 42, 6, 952-957, 1988.

Prenni, A. J., DeMott, P. J., Kreidenweis, S. M., Sherman, D. E., Russell, L. M., and Ming, Y.: The effects of low molecular weight dicarboxylic acids on cloud formation, J. Phys. Chem. A, 105, 50, 11240-11248, 2001.

Raymond, T. M. and Pandis, S. N.: Cloud activation of singlecomponent organic aerosol particles, J. Geophys. Res. A, 107, D24, AAC 16/1-AAC 16/8, 2002.

Rogge, W. F., Hildemann, L. M., Mazurek, M. A., Cass, G. R., and Simoneit, B. R. T.: Sources of Fine Organic Aerosol. 9. Pine, Oak, and Synthetic Log Combustion in Residential Fireplaces, Env. Sci. Techn., 32, 1, 13-22, 1998.
Rogge, W. F., Mazurek, M. A., Hildemann, L. M., Cass, G. R., and Simoneit, B. R. T.: Quantification of urban organic aerosols at a molecular level: identification, abundance and seasonal variation, Atmos. Envir., Part A: General Topics, 27A, 8, 1309-1330, 1993.

Saxena, P. and Hildemann, L. M.: Water-soluble organics in atmospheric particles: a critical review of the literature and application of thermodynamics to identify candidate compounds, J. Atmos. Chem., 24, 1, 57-109, 1996.

Sempere, R. and Kawamura, K.: Trans-hemispheric contribution of $\mathrm{C}_{2}-\mathrm{C}_{10}$ a, w-dicarboxylic acids, and related polar compounds to water-soluble organic carbon in the western Pacific aerosols in relation to photochemical oxidation reactions, Glob. Biogeochem. Cycl., 17, 2, 38/1-38/15, 2003.

Simoneit, B. R. T.: Characterization of organic constituents in aerosols in relation to their origin and transport: a review, Int. J. Env. Analyt. Chem., 23, 3, 207-237, 1986.

Turpin, B. J., Saxena, P., and Andrews, E.: Measuring and simulating particulate organics in the atmosphere: problems and prospects, Atmos. Envir., 34, 18, 2983-3013, 2000.

Twomey, S. A., Piepgrass, M., and Wolfe, T. L.: An assessment of the impact of pollution of global cloud albedo, Tellus, Ser. B, 36B, 5, 356-366, 1984.

Warneck, P.: In-cloud chemistry opens pathway to the formation of oxalic acid in the marine atmosphere, Atmos. Envir., 37, 17, 2423-2427, 2003.

Wiscomb, W. J.: Improved Mie scattering algorithms, Appl. Opt., 19, 1505-1509, 1980.

Yao, X., Fang, M., and Chan, C. K.: Size distributions and formation of dicarboxylic acids in atmospheric particles, Atmos. Envir., 36, 13, 2099-2107, 2002.

Zappoli, S., Andracchio, A., Fuzzi, S., Facchini, M. C., Gelencser, A., Kiss, G., Krivacsy, Z., Molnar, A., Meszaros, E., Hansson, H. C., Rosman, K., and Zebuhr, Y.: Inorganic, organic and macromolecular components of fine aerosol in different areas of Europe in relation to their water solubility, Atmos. Envir., 33, 17, 2733-2743, 1999. 